\title{
What information and the extent of information research participants need in informed consent forms: a multi-country survey
}

Juntra Karbwang ${ }^{1 *}$, Nut Koonrungsesomboon ${ }^{2 *}$ (D), Cristina E. Torres ${ }^{3,4}$, Edlyn B. Jimenez ${ }^{4}$, Gurpreet Kaur ${ }^{5}$, Roli Mathur ${ }^{6}$, Eti N. Sholikhah7, Chandanie Wanigatunge ${ }^{8}$, Chih-Shung Wong ${ }^{9}$, Kwanchanok Yimtae $^{10}$, Murnilina Abdul Malek ${ }^{11}$, Liyana Ahamad Fouzi ${ }^{12}$, Aisyah Ali ${ }^{13}$, Beng Z. Chan ${ }^{14}$, Madawa Chandratilake ${ }^{15}$, Shoen C. Chiew ${ }^{16}$, Melvyn Y. C. Chin ${ }^{17}$, Manori Gamage ${ }^{18}$, Irene Gitek ${ }^{19}$, Mohammad Hakimi ${ }^{20}$, Narwani Hussin ${ }^{21}$, Mohd F. A. Jamil ${ }^{22}$, Pavithra Janarsan ${ }^{23}$, Madarina Julia ${ }^{24}$, Suman Kanungo ${ }^{25}$, Panduka Karunanayake ${ }^{26}$, Sattian Kollanthavelu ${ }^{27}$, Kian K. Kong ${ }^{28}$, Bing-Ling Kueh ${ }^{29}$, Ragini Kulkarni ${ }^{30}$, Paul P. Kumaran ${ }^{31}$, Ranjith Kumarasiri ${ }^{32}$, Wei H. Lim³ ${ }^{33}$ Xin J. Lim³ ${ }^{34}$ Fatihah Mahmud ${ }^{35}$, Jacinto B. V. Mantaring III ${ }^{36}$, Siti M. Md Ali ${ }^{37}$, Nurain Mohd Noor ${ }^{38}$, Kopalasuntharam Muhunthan ${ }^{39}$, Elanngovan Nagandran ${ }^{40}$, Maisarah Noor ${ }^{41}$, Kim H. Ooi ${ }^{42}$, Jebananthy A. Pradeepan ${ }^{39}$, Ahmad H. Sadewa ${ }^{43}$, Nilakshi Samaranayake ${ }^{26}$, Shalini Sri Ranganathan ${ }^{26}$, Wasanthi Subasingha ${ }^{15}$, Sivasangari Subramaniam ${ }^{44}$, Nadirah Sulaiman ${ }^{45}$, Ju F. Tay ${ }^{46}$, Leh H. Teng ${ }^{47}$, Mei M. Tew ${ }^{48}$, Thipaporn Tharavanij ${ }^{49}$, Peter S. K. Tok ${ }^{50}$, Jayanie Weeratna ${ }^{51}$, Tri Wibawa ${ }^{52}$, Renu Wickremasinghe ${ }^{18}$, Phanthipha Wongwai ${ }^{53}$, Subhash Yadav ${ }^{54}$ and FERCAP Multi-Country Research Team

\footnotetext{
Abstract to 5 (very important).

(Continued on next page)

*Correspondence: karbwangj@nagasaki-u.ac.jp; jkarbwang@yahoo.com; nut.koonrung@cmu.ac.th; nkoonrung@gmail.com

${ }^{1}$ Department of Clinical Product Development, Institute of Tropical Medicine, Nagasaki University, 1-12-4 Sakamoto, Nagasaki 852-8523, Japan

2Department of Pharmacology, Faculty of Medicine, Chiang Mai University,

110 Muang Chiang Mai, Chiang Mai 50200, Thailand

Full list of author information is available at the end of the article
}

Background: The use of lengthy, detailed, and complex informed consent forms (ICFs) is of paramount concern in biomedical research as it may not truly promote the rights and interests of research participants. The extent of information in ICFs has been the subject of debates for decades; however, no clear guidance is given. Thus, the objective of this study was to determine the perspectives of research participants about the type and extent of information they need when they are invited to participate in biomedical research.

Methods: This multi-center, cross-sectional, descriptive survey was conducted at 54 study sites in seven AsiaPacific countries. A modified Likert-scale questionnaire was used to determine the importance of each element in the ICF among research participants of a biomedical study, with an anchored rating scale from 1 (not important)

(c) The Author(s). 2018 Open Access This article is distributed under the terms of the Creative Commons Attribution 4.0 International License (http://creativecommons.org/licenses/by/4.0/), which permits unrestricted use, distribution, and reproduction in any medium, provided you give appropriate credit to the original author(s) and the source, provide a link to the Creative Commons license, and indicate if changes were made. The Creative Commons Public Domain Dedication waiver (http://creativecommons.org/publicdomain/zero/1.0/) applies to the data made available in this article, unless otherwise stated. 
(Continued from previous page)

Results: Of the 2484 questionnaires distributed, 2113 (85.1\%) were returned. The majority of respondents considered most elements required in the ICF to be 'moderately important' to 'very important' for their decision making (mean score, ranging from 3.58 to 4.47). Major foreseeable risk, direct benefit, and common adverse effects of the intervention were considered to be of most concerned elements in the ICF (mean score $=4.47$, 4 . 47, and 4.45, respectively).

Conclusions: Research participants would like to be informed of the ICF elements required by ethical guidelines and regulations; however, the importance of each element varied, e.g., risk and benefit associated with research participants were considered to be more important than the general nature or technical details of research. Using a participant-oriented approach by providing more details of the participant-interested elements while avoiding unnecessarily lengthy details of other less important elements would enhance the quality of the ICF.

Keywords: Consent forms, Informed consent, Disclosure, Information, Ethics, Research subjects

\section{Background}

An informed consent form (ICF) is mandatory and essential in most studies involving human subjects as it is a primary vehicle for disclosure of information and documentation of consent $[1,2]$. An observation of the current research practice reveals that ICFs continue to increase in length and complexity in an attempt to comply with regulatory requirements [3-6], which increasingly require more and more elements to address past and present unethical practice [7, 8]. Lengthy and complex ICFs decrease the ability of potential participants to comprehend the ICF content and exercise their autonomy in decision making to participate in a study [9]. ICFs have been gradually turned into legal documents for the protection of researchers and sponsors rather than documents with relevant information for decision making of research participants [10].

In an attempt to make ICFs comprehensible, the extent of information disclosure has been the subject of debates [11-13]. Lengthy ICFs with full disclosure of everything may obscure the important and relevant information for decision making whether to participate in a study [14]. Exhaustive disclosure of detailed information of every single aspect related to the study may overwhelm potential research participants with too excessive information [15]. Based on a systematic review on the desired information by potential participants of biomedical research, there is limited empirical evidence on this subject [16]. Generally, the type and extent of information considered as adequate and relevant for a person to make a decision are subjective and difficult to define. In addition, some information perceived as relevant and important by some research participants, with respect to their cultural context, may be absent in even a lengthy ICF as it is not required by applicable laws and regulations [13]. To address these issues, empirical data related to the content and extent of information that research participants require for their decision making are needed. The objective of this study was to determine the perspectives of research participants about the information they need for their decision making when they are invited to participate in biomedical research.

\section{Methods \\ Study design and settings}

This multi-center, cross-sectional, descriptive survey was conducted by the Forum for Ethical Review Committees in the Asian and Western Pacific region (FERCAP) Multi-Country Research Team in 7 FERCAP-member countries, i.e., India, Indonesia, Malaysia, Philippines, Sri Lanka, Taiwan, and Thailand. The duration of this study was three months, from June 1 to August 31, 2017, with a two-week extension in some countries where a sample size was not met within the three-month period.

\section{Study material}

An anonymous, paper-based, structured and self-administered questionnaire was developed and reviewed by a group of FERCAP professionals with expertise in research surveys, biomedical research, research ethics, and informed consent. Survey items were developed based on the essential elements required by three major ethical guidelines and regulations, i.e., Declaration of Helsinki [1], the International Conference on Harmonization ( $\mathrm{ICH}$ ) for Good Clinical Practice (GCP) [2], and US Code of Federal Regulations [17]. A content validity test was conducted to establish that individual items were relevant to the construct being measured and that key items had not been omitted in the questionnaire [18]. The questionnaire asked participants to indicate how important each item was by giving a rating from 1 to 5 using a modified Likert scale [19]: 1 = not important, 2 = slightly important, 3 = moderately important, 4 =fairly important, and $5=$ very important. There were open-ended questions in the questionnaire where the participants could suggest any additional elements or information that they would like to receive. Demographic data (age, sex, educational level, nationality, and occupation) and the participants' preference in page length were included in the questionnaire. 
The think-aloud technique was used to assess how respondents interpreted each item and response anchor [20]. The questionnaire was then finalized and translated into the local language for use in each participating country. The questionnaires in local languages were back-translated into English by independent individuals who are fluent in both local and English languages and checked against the original questionnaire. The translated questionnaire was piloted in a small group of individuals who were members of the target population within each respective country.

\section{Study population and sample size determination}

This study enrolled individuals who were participating in ongoing biomedical research - a research study relating to biology and medicine for healthcare purposes - at various participating centers (clinical research units or comparable settings) in 7 countries. Individuals who refused to answer the questionnaire for any reason or had communication difficulties due to language problems or cognitive disabilities were excluded.

The sample size for this study was meant to yield a representative sample under the assumption that the quantity of interest is measured by a Likert scale. Following the formula described in Park \& Jung (2009) [21], a sample size of at least 231 would be adequate when a 5-point scale was used for each Likert-item $(k=5)$, with a coefficient of variation of a population $(C)=0.5$, a relative tolerable error $(D)=5 \%$, and a pairwise correlation coefficient $(\rho)=0.5$. The present study was initially planned to enrol, at least, 300 participants in each country based on an approximate estimate of $20 \%$ of missing data due to some participants who might skip certain questions or items that they were not comfortable with.

\section{Study procedure and data collection}

Data were collected through an anonymous, self-administered, structured, paper-based questionnaire. No written consent was required for this survey study as an individual participant's voluntary completion of the questionnaire was presumed as consent. Site investigators collaborated with research staff at clinical research units or comparable settings and informed research participants in biomedical research about this ICF study. Instructions were provided by research staff to potential participants that they could refuse to answer the questionnaire for any reason; they could skip any question that they were unwilling to answer; and they would not be treated differently because of the responses they gave in the questionnaire. When participants agreed to take part in this survey, research staff gave them the questionnaire. The participants could complete the questionnaire at any time and returned it to the collection box located at participating centers.

\section{Ethical considerations}

The study was conducted in compliance with the Declaration of Helsinki 2013. The study protocol and related documents obtained ethical approval from local ethics committees prior to the commencement of the survey in each center. This study was considered 'minimal-risk' research since it involved only the use of a questionnaire with no sensitive questions. The information was recorded in an anonymous manner. The participants could skip any question that they did not want to answer. Answering the questionnaire and returning it to the collection box implied the participants' voluntary consent for the investigators to use their answers to meet the research objective. No separate written consent was required to ensure the participants' anonymity.

\section{Statistical analysis}

Data from 7 countries were gathered, analyzed, and presented as frequency and percentage, mean and standard deviation (SD), or median and interquartile range (IQR), as appropriate. For the participants' preference in page length, 'no limit' or more than 30 pages was transformed to the value of 30 for analysis. Likert scale responses of each item were analyzed using parametric approaches [22-24]. Differences of variables among countries were done using the one-way analysis of variance (ANOVA), followed by Tukey post hoc test. The association between independent variables (i.e., sex, age, education, occupation, and type of research involved) and the mean score of each item was assessed using multivariable regression analysis. Statistical analyses were performed using SPSS (IBM Corp. Release 2013. IBM SPSS Statistics for Windows, Version 22.0. Armonk, NY: IBM Corp). A $p$ value of less than 0.05 was considered to indicate statistical significance.

\section{Results}

This FERCAP Multi-Country ICF study recruited research participants from 54 study sites in 7 countries. Of the 2484 questionnaires distributed, 2113 (85.1\%) were returned (Table 1). Demographic data of the respondents are shown in Table 2. The majority of the respondents were female (57.9\%), middle-aged adults (aged $43.3 \pm$ 16.2 years, range 15-90 years), had a high-school level of education or lower (64.5\%).

Overall, the respondents wanted to know most elements of the ICF content required (Table 3), with mean scores ranging from 3.58 (about wanting to know the number of participants) to 4.47 (for major foreseeable risk) as shown in Fig. 1. All of the 37 items were rated as 'moderately important' or higher among approximately $80 \%$ of the respondents to as high as $97.4 \%$ of them highly interested in the direct benefit of research (see Additional file 1: Table S1). None of the items were 
Table 1 Number of questionnaires distributed and collected by each country

\begin{tabular}{|c|c|c|c|c|}
\hline \multirow{2}{*}{$\frac{\text { Country }}{\text { India }}$} & \multirow{2}{*}{$\frac{\text { Site }(n)}{4}$} & \multirow{2}{*}{$\begin{array}{l}\text { Questionnaires distributed }(n) \\
434\end{array}$} & \multicolumn{2}{|c|}{ Questionnaires collected $(n)$} \\
\hline & & & 410 & $(94.5 \%)$ \\
\hline Indonesia & 1 & 362 & 299 & $(82.6 \%)$ \\
\hline Malaysia & 28 & 508 & 508 & $(100.0 \%)$ \\
\hline Philippines & 12 & 508 & 267 & $(52.6 \%)$ \\
\hline Sri Lanka & 6 & 335 & 303 & $(90.4 \%)$ \\
\hline Taiwan & 1 & 229 & 229 & $(100.0 \%)$ \\
\hline \multirow[t]{2}{*}{ Thailand } & 2 & 108 & 97 & $(89.8 \%)$ \\
\hline & 54 & 2484 & 2113 & (85.1\%) \\
\hline
\end{tabular}

considered 'slightly important' or lower in more than one-third of the respondents from any country. Statistically significant differences were found among countries in the mean score of all the 37 items when one-way ANOVA was applied $(p<0.001)$ (data not shown).

Major foreseeable risk, direct benefit, and common adverse effects of the intervention were considered to be of most concern among the respondents (with mean scores of 4.47, 4.47, and 4.45, respectively) as shown in Fig. 1. In contrast, items about payment and/or remuneration, conflict of interest, the source of funds and sponsors, and the number of participants involved were considered to be of relatively less concern (with mean scores of $3.85,3.79,3.75$, and 3.58, respectively). Nevertheless, there was slight variation in the items that were of most

Table 2 Demographic data of the respondents

\begin{tabular}{|c|c|c|}
\hline Characteristics of the respondents & $n(\%)$ & \\
\hline \multicolumn{3}{|l|}{ Sex } \\
\hline Male & 884 & $(42.1 \%)$ \\
\hline Female & 1215 & $(57.9 \%)$ \\
\hline \multicolumn{3}{|l|}{ Age } \\
\hline $15-30$ years & 638 & $(30.4 \%)$ \\
\hline $31-45$ years & 546 & $(26.0 \%)$ \\
\hline $46-60$ years & 514 & $(24.5 \%)$ \\
\hline $61-90$ years & 401 & $(19.1 \%)$ \\
\hline \multicolumn{3}{|l|}{ Educational level } \\
\hline High school or lower & 1331 & $(64.5 \%)$ \\
\hline Bachelor/diploma degree & 525 & $(25.4 \%)$ \\
\hline Master/doctor degree & 208 & $(10.1 \%)$ \\
\hline \multicolumn{3}{|l|}{ Occupation } \\
\hline Healthcare profession & 245 & $(12.4 \%)$ \\
\hline Non-healthcare profession ${ }^{\dagger}$ & 1730 & $(87.6 \%)$ \\
\hline \multicolumn{3}{|l|}{ Type of research involved } \\
\hline Experimental research & 1234 & $(59.8 \%)$ \\
\hline Observational research & 830 & $(40.2 \%)$ \\
\hline
\end{tabular}

${ }^{\dagger}$ Non-healthcare profession, including students, housewives, retirees, and the unemployed and of least concern among research participants in different countries (Table 4).

Demographic characteristics were found to be associated with the scores in several items. Higher scores in the desire to receive detailed information were associated with female gender (in 34 out of the 37 items), healthcare profession (in 24 out of the 37 items), younger age (in 11 out of the 37 items), and higher educational levels (in 10 out of the 37 items) (see Additional file 2: Table S2). Those participating in experimental research wanted more information in 30 out of the 37 items, as compared to those participating in observational research.

The maximum, acceptable number of pages in the ICF that research participants preferred to read was $6.3 \pm 6.1$ pages (median, 5 pages; IQR, 2-8 pages). However, this value varied among countries. The Taiwanese respondents reported the longest maximum, acceptable number of pages that they would read $(12.3 \pm 10.8$ pages, $n=174)$, followed by the Filipino $(7.7 \pm 6.5$ pages, $n=200)$, Malaysian $(7.0 \pm 5.7$ pages, $n=438)$, Thai $(5.3 \pm 3.1$ pages, $n=22)$, Indian $(5.0 \pm 3.2$ pages, $n=378)$, Indonesian $(4.1 \pm 3.3$ pages, $n=242)$, and Sri Lankan respondents (3.7 \pm 3.3 pages, $n=213)$ (see Additional file 3: Table S3). Multivariable analysis identified factors that were associated with the maximum, acceptable number of pages in the ICF, i.e., occupation (healthcare profession vs. non-healthcare profession, $p<0.001$ ) and type of research involved (experimental vs. observational, $p<0.001$ ). When compared to their counterparts, research participants in the healthcare profession and those participating in the experimental research were more agreeable to reading longer ICFs ( 8.6 vs. 5.9 pages, $p<0.001 ; 6.8$ vs. 5.5 pages, $p<0.001$, respectively) (see Additional file 4: Figure S1).

There were 58 comments from 56 respondents, suggesting additional information needs. The majority of these comments showed their desire to know about whether to be informed of research results $(n=37)$ and the location where the research will be conducted $(n=8)$. A few respondents mentioned that they wanted to receive information about legal liability related to research $(n=4)$, other study sites involved $(n=2)$, clinical phase of the trial 
Table 3 The element and extent of information that research participants wanted to receive

\begin{tabular}{|c|c|c|c|c|c|c|c|}
\hline \multirow[t]{2}{*}{ Element } & \multirow[t]{2}{*}{ Abbreviation } & \multirow[t]{2}{*}{ n } & \multicolumn{5}{|c|}{ Extent of information } \\
\hline & & & Mean & SE & SD & Median & IQR \\
\hline \multicolumn{8}{|l|}{ 1. General items } \\
\hline 1.1 Title of research & Title & $(n=2100)$ & 4.33 & 0.021 & 0.941 & 5 & $(4-5)$ \\
\hline 1.2 Name of researchers & Name & $(n=2091)$ & 4.08 & 0.024 & 1.088 & 4 & $(4-5)$ \\
\hline 1.3 Affiliation or organization of researchers & Affil & $(n=2083)$ & 4.10 & 0.023 & 1.035 & 4 & $(4-5)$ \\
\hline 1.4 Recognition that this is research & Resea & $(n=2095)$ & 4.29 & 0.021 & 0.963 & 5 & $(4-5)$ \\
\hline 1.5 Contact information regarding the research study & clnfo & $(n=2040)$ & 4.29 & 0.020 & 0.899 & 5 & $(4-5)$ \\
\hline 1.6 Contact information about the participant's right & ClnfoR & $(n=2035)$ & 4.26 & 0.021 & 0.932 & 5 & $(4-5)$ \\
\hline 1.7 Source of funds and sponsors & Spons & $(n=2082)$ & 3.75 & 0.027 & 1.233 & 4 & $(3-5)$ \\
\hline 1.8 Conflict of interest & Coi & $(n=2020)$ & 3.79 & 0.027 & 1.228 & 4 & $(3-5)$ \\
\hline \multicolumn{8}{|l|}{ 2. Study-specific items } \\
\hline 2.1 Background and rationale of research & Backg & $(n=2084)$ & 4.16 & 0.021 & 0.966 & 4 & $(4-5)$ \\
\hline 2.2 Purpose of research & Purp & $(n=2093)$ & 4.35 & 0.019 & 0.868 & 5 & $(4-5)$ \\
\hline 2.3 Eligibility of the participant & Eligib & $(n=2104)$ & 4.28 & 0.020 & 0.915 & 5 & $(4-5)$ \\
\hline 2.4 Study design of research & Desig & $(n=2078)$ & 3.96 & 0.023 & 1.071 & 4 & $(3-5)$ \\
\hline 2.5 Interventions under investigation & Interv & $(n=2080)$ & 4.37 & 0.020 & 0.895 & 5 & $(4-5)$ \\
\hline 2.6 Common adverse effects of the intervention & $\mathrm{COAE}$ & $(n=2082)$ & 4.45 & 0.019 & 0.857 & 5 & $(4-5)$ \\
\hline 2.7 All possible adverse effects of the intervention & allAE & $(n=2086)$ & 4.36 & 0.020 & 0.933 & 5 & $(4-5)$ \\
\hline 2.8 Other options or alternative treatments & Altern & $(n=2088)$ & 4.02 & 0.024 & 1.093 & 4 & $(3-5)$ \\
\hline 2.9 Duration of the participant's participation & Durat & $(n=2069)$ & 4.17 & 0.021 & 0.971 & 4 & $(4-5)$ \\
\hline 2.10 Schedule and procedure & Proc & $(n=2089)$ & 4.29 & 0.020 & 0.894 & 5 & $(4-5)$ \\
\hline 2.11 Identification of any experimental procedures & eProc & $(n=2075)$ & 4.11 & 0.022 & 1.013 & 4 & $(4-5)$ \\
\hline 2.12 Number of participants involved & Numb & $(n=2092)$ & 3.58 & 0.027 & 1.218 & 4 & $(3-5)$ \\
\hline 2.13 Criteria for termination & Term & $(n=2045)$ & 4.23 & 0.022 & 0.975 & 4 & $(4-5)$ \\
\hline \multicolumn{8}{|l|}{ 3. Items related to the subject's right } \\
\hline 3.1 Voluntary participation & Volun & $(n=2093)$ & 4.19 & 0.022 & 1.014 & 4 & $(4-5)$ \\
\hline 3.2 Consequence of withdrawal & cWith & $(n=2039)$ & 4.04 & 0.024 & 1.097 & 4 & $(4-5)$ \\
\hline 3.3 Right to receive new information & nlnfo & $(n=2048)$ & 4.25 & 0.020 & 0.927 & 4 & $(4-5)$ \\
\hline \multicolumn{8}{|l|}{ 4. Items related to risk-benefit } \\
\hline 4.1 Major foreseeable risk & mjis & $(n=2077)$ & 4.47 & 0.020 & 0.902 & 5 & $(4-5)$ \\
\hline 4.2 Minor foreseeable risk & miRis & $(n=2077)$ & 4.25 & 0.021 & 0.968 & 5 & $(4-5)$ \\
\hline 4.3 Possibly unforeseeable risk & ufRis & $(n=2043)$ & 4.27 & 0.024 & 1.064 & 5 & $(4-5)$ \\
\hline 4.4 Direct health benefit & dBene & $(n=2088)$ & 4.47 & 0.017 & 0.793 & 5 & $(4-5)$ \\
\hline 4.5 Indirect benefit & iBene & $(n=2096)$ & 4.31 & 0.019 & 0.865 & 5 & $(4-5)$ \\
\hline 4.6 Societal benefit & sBene & $(n=2049)$ & 4.30 & 0.020 & 0.901 & 5 & $(4-5)$ \\
\hline 4.7 Post-trial benefit or provision & pBene & $(n=2048)$ & 4.23 & 0.021 & 0.950 & 4 & $(4-5)$ \\
\hline \multicolumn{8}{|l|}{ 5. Items related to data and sample storage } \\
\hline 5.1 Confidentiality and the limit of confidentiality & Confi & $(n=2048)$ & 4.29 & 0.022 & 0.984 & 5 & $(4-5)$ \\
\hline 5.2 Storage of human material & Stora & $(n=2041)$ & 3.97 & 0.025 & 1.148 & 4 & $(3-5)$ \\
\hline 5.3 Reuse of human material & Reuse & $(n=2043)$ & 4.04 & 0.025 & 1.113 & 4 & $(4-5)$ \\
\hline \multicolumn{8}{|l|}{ 6. Items related to monetary issues } \\
\hline 6.1 Payment and/or remuneration & Paym & $(n=2040)$ & 3.85 & 0.026 & 1.156 & 4 & $(3-5)$ \\
\hline 6.2 Anticipated expense & Expen & $(n=2025)$ & 4.00 & 0.024 & 1.099 & 4 & $(4-5)$ \\
\hline 6.3 Compensation for injury & Compe & $(n=2038)$ & 4.32 & 0.020 & 0.912 & 5 & $(4-5)$ \\
\hline
\end{tabular}




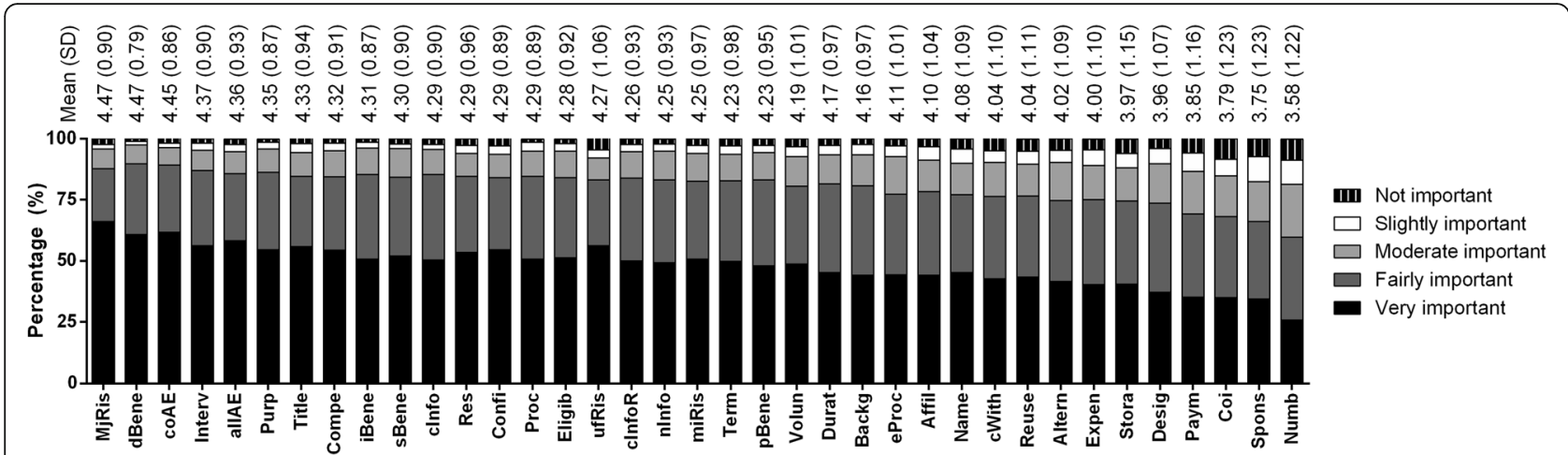

Fig. 1 The element and extent of information that research participants wanted to receive

$(\mathrm{n}=2)$, status of the trial, testimony, and approval $(\mathrm{n}=2)$, research budget $(n=2)$, and related sources of information $(\mathrm{n}=1)$.

\section{Discussion}

This FERCAP Multi-Country ICF study is the largest empirical study on this subject, involving 2113 actual research participants from 54 study sites in 7 countries. It attempted to determine the information that research participants considered to be of importance for their decision making whether to participate in biomedical research. The results indicate that the ICF elements required by ethical guidelines and regulations concur with the information the majority of research participants in 7 Asia-Pacific countries want to know.

The top three items which were of most concern to the respondents in this study were related to the concepts of risks and benefits (i.e., major foreseeable risk, direct benefit, and common adverse effects of the intervention). This finding is consistent with previous numerous studies indicating that research participants regard the risk and benefit associated with their participation to be more important than the general nature or technical details of research [25-27]. Thus, such information should be made a salient feature of an ICF when enrolling potential participants. While the written ICF provided in biomedical research should contain the necessary elements, it should be properly edited and streamlined to ensure concise information to reflect the results of this study. A participant-oriented approach that considers the importance of each element and emphasis on items perceived as more important than others could adequately address participant needs and avoid unnecessarily lengthy details that are of no interest to them [13]. Information should be provided to the extent that it does not detract from what participants want to know and what is needed for a valid consent (i.e., sufficient information, comprehension, and voluntariness) [28]. Information relating to the concepts of risks and benefits, for example, should be described extensively and made salient to potential research participants, while the general nature or technical details of research can be described briefly.

Disclosure requirements based on the elements required in the three major ethical guidelines and regulations - the Declaration of Helsinki [1], ICH GCP [2], and US federal regulations [17] - are generally sufficient to cover all the aspects that most research participants would like to know. However, this study identified additional information that some participants want to be informed about. Information regarding the disclosure of individual results to participants at the end of the study is one of the elements that a sizable number of participants would like to know. This finding is in line with a recent systematic review reporting that several participants wanted to be told about dissemination of study results [16]. This issue has lately been addressed in the revised US Federal Policy for the Protection of Human Subjects, promulgated in January 2017, that requires " $a$ statement regarding whether clinically relevant research results, including individual research results, will be disclosed to subjects, and if so, under what conditions" [7]. Nevertheless, it is important to note that disclosure of individual research results (IRRs) might pose psychosocial risks to research participants and their relatives in some settings, especially in genetic-association research [29]. Hence, conditions for disclosure of IRRs should be predefined, e.g., the results that will be conveyed to the participants should be analytically valid, medically important, and actionable, with respect to the participants' preference [30-32]. In addition, a few respondents raised concerns about legal liability related to research while another wanted to know other study sites involved. When individuals would like to obtain certain additional information that may be relevant to their concerns, investigators may be required to disclose or provide them on a case-by-case basis [28].

The analysis of the respondents' acceptable page length suggests that an approximately 6-page-long ICF seems to be acceptable to general populations in 7 
Table 4 Ranks of the elements considered to be of most concern by research participants from each country

\begin{tabular}{|c|c|c|c|c|c|c|c|c|c|c|c|c|c|c|c|c|}
\hline \multirow{3}{*}{ Rank } & \multirow{2}{*}{\multicolumn{2}{|c|}{7 countries }} & \multirow{2}{*}{\multicolumn{2}{|c|}{ India }} & \multirow{2}{*}{\multicolumn{2}{|c|}{ Indonesia }} & \multirow{2}{*}{\multicolumn{2}{|c|}{ Malaysia }} & \multirow{2}{*}{\multicolumn{2}{|c|}{ Philippines }} & \multirow{2}{*}{\multicolumn{2}{|c|}{ Sri Lanka }} & \multirow{2}{*}{\multicolumn{2}{|c|}{ Taiwan }} & \multirow{2}{*}{\multicolumn{2}{|c|}{ Thailand }} \\
\hline & & & & & & & & & & & & & & & & \\
\hline & Item & Mean & Item & Mean & Item & Mean & Item & Mean & Item & Mean & Item & Mean & Item & Mean & Item & Mean \\
\hline 1 & mjRis & 4.47 & dBene & 4.43 & dBene & 4.26 & dBene & 4.51 & mjRis & 4.55 & dBene & 4.58 & coAE & 4.74 & mjRis & 4.42 \\
\hline 2 & dBene & 4.47 & mjRis & 4.42 & coAE & 4.18 & Purp & 4.50 & dBene & 4.55 & coAE & 4.54 & mjRis & 4.73 & $\operatorname{coAE}$ & 4.41 \\
\hline 3 & coAE & 4.45 & Interv & 4.41 & mjRis & 4.18 & mjRis & 4.50 & iBene & 4.54 & Title & 4.52 & allAE & 4.71 & allAE & 4.37 \\
\hline 4 & Interv & 4.37 & coAE & 4.41 & Confi & 4.16 & coAE & 4.46 & coAE & 4.46 & Volun & 4.51 & Res & 4.66 & Interv & 4.36 \\
\hline 5 & allAE & 4.36 & Eligib & 4.39 & Interv & 4.14 & allAE & 4.43 & allAE & 4.46 & mjRis & 4.51 & Compe & 4.64 & dBene & 4.28 \\
\hline 6 & Purp & 4.35 & sBene & 4.36 & cInfo & 4.14 & Title & 4.40 & Interv & 4.44 & Compe & 4.51 & ufRis & 4.63 & Confi & 4.21 \\
\hline 7 & Title & 4.33 & iBene & 4.35 & Title & 4.13 & sBene & 4.39 & Purp & 4.44 & Proc & 4.44 & Volun & 4.56 & miRis & 4.19 \\
\hline 8 & Compe & 4.32 & allAE & 4.32 & ufRis & 4.12 & Res & 4.38 & sBene & 4.44 & Purp & 4.42 & Interv & 4.55 & Purp & 4.07 \\
\hline 9 & iBene & 4.31 & ufRis & 4.32 & Compe & 4.09 & Interv & 4.38 & Term & 4.42 & Confi & 4.41 & dBene & 4.54 & iBene & 4.07 \\
\hline 10 & sBene & 4.30 & Proc & 4.31 & Backg & 4.08 & Proc & 4.37 & nInfo & 4.41 & sBene & 4.40 & Confi & 4.54 & nInfo & 4.07 \\
\hline 11 & cInfo & 4.29 & cInfo & 4.31 & iBene & 4.07 & iBene & 4.36 & Proc & 4.40 & cInfo & 4.39 & Altern & 4.52 & Volun & 4.06 \\
\hline 12 & Res & 4.29 & cInfoR & 4.30 & Purp & 4.04 & Compe & 4.35 & pBene & 4.39 & Eligib & 4.38 & Title & 4.51 & Res & 4.03 \\
\hline 13 & Confi & 4.29 & Purp & 4.29 & Affil & 4.03 & cInfo & 4.35 & cInfo & 4.39 & Term & 4.38 & Proc & 4.51 & Stora & 4.02 \\
\hline 14 & Proc & 4.29 & Compe & 4.28 & cInfoR & 4.03 & Term & 4.32 & Durat & 4.36 & Res & 4.37 & Term & 4.51 & Reuse & 4.00 \\
\hline 15 & Eligib & 4.28 & Res & 4.27 & sBene & 4.01 & Confi & 4.32 & Confi & 4.36 & miRis & 4.36 & eProc & 4.50 & Title & 3.99 \\
\hline 16 & ufRis & 4.27 & Title & 4.25 & allAE & 3.99 & Eligib & 4.31 & Backg & 4.35 & iBene & 4.36 & miRis & 4.50 & sBene & 3.99 \\
\hline 17 & cInfoR & 4.26 & nInfo & 4.23 & Eligib & 3.97 & nInfo & 4.31 & cInfoR & 4.35 & nInfo & 4.36 & Eligib & 4.48 & Eligib & 3.98 \\
\hline 18 & nInfo & 4.25 & pBene & 4.20 & miRis & 3.97 & cInfoR & 4.31 & eProc & 4.34 & Durat & 4.35 & Purp & 4.46 & ufRis & 3.96 \\
\hline 19 & miRis & 4.25 & Durat & 4.19 & pBene & 3.97 & Name & 4.29 & miRis & 4.31 & cInfoR & 4.34 & nInfo & 4.46 & Term & 3.95 \\
\hline 20 & Term & 4.23 & miRis & 4.19 & Name & 3.96 & pBene & 4.27 & cWith & 4.29 & allAE & 4.32 & Expen & 4.42 & Durat & 3.92 \\
\hline 21 & pBene & 4.23 & Backg & 4.15 & Term & 3.95 & miRis & 4.26 & Compe & 4.28 & ufRis & 4.32 & Reuse & 4.39 & Compe & 3.92 \\
\hline 22 & Volun & 4.19 & Name & 4.12 & Res & 3.92 & Affil & 4.25 & ufRis & 4.26 & cWith & 4.32 & pBene & 4.38 & Name & 3.91 \\
\hline 23 & Durat & 4.17 & Confi & 4.12 & eProc & 3.84 & Backg & 4.23 & Eligib & 4.25 & pBene & 4.32 & cInfoR & 4.38 & cWith & 3.91 \\
\hline 24 & Backg & 4.16 & Volun & 4.07 & nInfo & 3.84 & Durat & 4.19 & Title & 4.24 & Interv & 4.31 & Durat & 4.37 & Proc & 3.88 \\
\hline 25 & eProc & 4.11 & Altern & 4.06 & Proc & 3.83 & eProc & 4.19 & Res & 4.24 & Desig & 4.18 & cWith & 4.36 & pBene & 3.88 \\
\hline 26 & Affil & 4.10 & Term & 4.05 & Reuse & 3.82 & $\begin{array}{l}\text { Volun } \\
\end{array}$ & 4.18 & Volun & 4.23 & Altern & 4.17 & cInfo & 4.32 & cInfoR & 3.85 \\
\hline 27 & Name & 4.08 & Affil & 4.02 & Paym & 3.78 & ufRis & 4.18 & Reuse & 4.21 & Backg & 4.16 & Affil & 4.31 & Desig & 3.81 \\
\hline 28 & cWith & 4.04 & eProc & 4.02 & Volun & 3.74 & Stora & 4.09 & Coi & 4.18 & Expen & 4.15 & Stora & 4.31 & cInfo & 3.81 \\
\hline 29 & Reuse & 4.04 & cWith & 4.02 & Desig & 3.73 & Expen & 4.03 & Stora & 4.16 & Affil & 4.02 & Coi & 4.30 & eProc & 3.77 \\
\hline 30 & Altern & 4.02 & Reuse & 3.96 & Durat & 3.71 & Spons & 4.02 & Expen & 4.14 & eProc & 4.00 & Desig & 4.25 & Affil & 3.75 \\
\hline 31 & Expen & 4.00 & Desig & 3.91 & Expen & 3.68 & Reuse & 4.02 & Affil & 4.08 & Reuse & 4.00 & sBene & 4.24 & Altern & 3.73 \\
\hline 32 & Stora & 3.97 & Stora & 3.91 & Altern & 3.66 & cWith & 4.01 & Altern & 4.08 & Stora & 3.88 & iBene & 4.17 & Coi & 3.68 \\
\hline 33 & Desig & 3.96 & Spons & 3.88 & Stora & 3.49 & Coi & 3.97 & Desig & 4.07 & Name & 3.87 & Name & 4.12 & Expen & 3.67 \\
\hline 34 & Paym & 3.85 & Expen & 3.83 & cWith & 3.48 & Altern & 3.89 & Name & 4.03 & Paym & 3.87 & Backg & 4.11 & Paym & 3.61 \\
\hline 35 & Coi & 3.79 & Numb & 3.79 & Numb & 3.27 & Paym & 3.86 & Paym & 4.00 & Coi & 3.48 & Paym & 4.11 & Backg & 3.59 \\
\hline 36 & Spons & 3.75 & Paym & 3.69 & Spons & 3.25 & Desig & 3.85 & Spons & 3.87 & Spons & 3.43 & Spons & 3.98 & Spons & 3.49 \\
\hline 37 & Numb & 3.58 & Coi & 3.63 & Coi & 3.25 & Numb & 3.55 & Numb & 3.73 & Numb & 3.39 & Numb & 3.84 & Numb & 3.40 \\
\hline
\end{tabular}

The values that are more than 'mean +1 SD' (considered to be of most concern) is in RED columns; those within 'mean \pm 1 SD' is in YELLOW columns; and those less than 'mean - 1 SD' (considered to be of least concern) is in GREEN columns

countries across the Asia-Pacific region. This result is in line with other evidence promoting the use of short and concise ICFs in biomedical research [33]. As shown in a previous empirical study on the preferred length of ICFs, most participants preferred concise, rather than detailed information when they made a decision on trial participation [11]. Another evidence also suggested that a concise ICF is as valid as a detailed, standard ICF to comply with ethical requirements [34]. Although concise forms may not be able to improve participants' satisfaction with the consent process in all settings, they still have other advantages to the readers as ones are less likely to thoroughly read long forms and wholly absorb extensive information [35]. Recently, there has been a major change in the ethical guidelines and regulations that encourages investigators and sponsors to summarize relevant and important information in a few pages [7, 8]. An ICF used in biomedical research should no longer be an unduly long document, with key information often being hard to find [33]. Concise ICFs with complete information as required by regulations can be developed, for example, using the SIDCER ICF methodology, which has recently been validated and published [36-39]. This methodology requires a thorough understanding of the 
protocol followed by the summarized information relevant to the interest and concerns of research participants [36]. Visual aids such as summary tables, highlighting keywords and pictographs should be used, when appropriate, to simplify and help participants understand detailed and complex information [36, 40]. Nevertheless, some groups of participants, such as the Taiwanese, might indicate a preference for a relatively longer ICF which contains more detailed and comprehensive information. Supplementary provision of detailed information could be offered to such groups in additional papers (e.g., appendices) or via websites [25, 33].

A closer examination revealed that female participants, healthcare professionals, younger age groups, and those with high educational levels wanted to receive more information about several items when compared to their counterparts. This indicates the different needs of different groups for relevant biomedical or clinical trial information [41]. Furthermore, research participants from different countries showed slight variation in their interests in each element. This is in line with other studies which suggested that information needs may somewhat vary across diverse socioeconomic backgrounds and cultural settings [42-44]. However, there is also a possibility that the difference of variables among countries might not be a genuine difference in ethical views; rather, it might be influenced by response styles across countries or cultural backgrounds [45].

The results of this extensive multi-country survey, involving over 2000 actual research participants at 54 study sites across 7 Asia-Pacific countries, may be considered to be representative of the perspectives of general populations in the Asia-Pacific region. However, this study has a limitation as it lacks data on the perspectives of those asked to provide surrogate consent for others (e.g., parents or other legally acceptable representatives). It is reasonable to assume that the content and extent of information needed among surrogates may be different from what we observed among actual research participants in this study $[46,47]$. In addition, different levels of research risk (e.g., low-risk studies with little or no intervention versus high-risk studies with invasive interventions) may result in different needs for trial information among research participants $[25,40]$. Further research is required to help tailor ICFs toward more specific types of biomedical research, including biobank research, and population subgroups, such as the study previously done by Casarett et al. for pain research [48].

\section{Conclusions}

In summary, what research participants would like to be informed of mostly concurred with the elements of the ICF content required by the current ethical guidelines and regulations. However, some elements may be more important than others and such information should be made salient to research participants. The study results provide important insights to better address the challenges of determining the extent of information in ICFs that is considered to be important and adequate from research participants' perspectives.

\section{Additional files}

Additional file 1: Table S1. The proportions of the respondents who wanted to know each element. (DOCX $20 \mathrm{~kb}$ )

Additional file 2: Table S2. Associations between the respondents' characteristics and their desire to know each element of the ICF content. (DOCX 28 kb)

Additional file 3: Table S3. The maximum, acceptable number of pages in the informed consent form and its comparisons among countries. (DOCX $16 \mathrm{~kb}$ )

Additional file 4: Figure S1. Differences in the acceptable page length among respondents with different genders, educational levels, occupations, and types of research involved. (TIF $512 \mathrm{~kb}$ )

\section{Acknowledgements}

We are thankful to Albert B. Albay Jr., Siti Zianadia Amiriliani, Tito C. Atienza, Clodoaido M. Caringal, Annielyn Beryl O. Cornel, Teresita S. De Guia, Maria Corazon A. De Ungria, Angela A. Du, Marcelito L. Durante, Marie Cherry Lynn S. Fernando, Joven Roque V. Gonong, Ma. Liza Antoinette M. Gonzales, Pramudji Hastuti, Victoria C. Idolor, Desak Ketut Indrasari Utami, Niken Indrastuti, Utcharee Intusoma, Saturnino P. Javier, Manuel C. Jorge II, Guia Elena Imelda R. Ladrera, Houng Bang Liew, Anna Lena L. Lopez, Harry Freitag Luglio Muhammad, Marissa B. Lukban, Rusdy Ghazali Malueka, Bernadette Heizel Manapat-Reyes, Ma. Cecilia S. Montalban, Ika Nuraita, Nuring Pangastuti, Elizabeth C. Paterno, Hanandyasto Angganindya Pratama, Anthony Sudono Riyad, Evelyn O. Salido, Darby E. Santiago, Joel M. Santiaguel, Catherine Lynn T. Silao, Heinrik Jude Martin S. Strebel, Prospero Ma. C. Tuaño, Teresita D.V. Tuazon, Ajeng Putri Tunjungsari, and Aileen D. Wang for their collaboration as Site Investigators on the conduct of research at participating centers. Thanks are also extended to Annaveve Rose M. Alaban, Paherathy Arunagirinathan, Vaishali Nitin Bhogate, Watchara Boonsawat, Manogaran C, Nandini Datta Chakaraborty, Metaramba K.G.B. Dilrukshi, Rajib Kishore Hazam, Tsui-Wen Hsu, Wei-Jia Jhang, Pornthep Kasermsiri, Srichai Krunsan, Chia-Long Lee, Jannette M. Marquez, Iranna Sidramappa Mashal, Chalach Mitprachapranee, Ratanawadee Na Nagara, Harini Natalia, Tungsukruthai Parunkul, Kranti Sudhakar Patankar, Chonlatip Pongsakul, Supatra Porasuphatana, Thongchai Pratipannawatr, Agustin Purnamawati, Wipa Reechaipichitkul, Sirirat Ruengjui, Praveen Shivaji Sanap, Piyumi Senanayake, Auemkae Sukprasert, Kalyani Thakur, Triyanto, and Banu Rekha W for their assistance in administrative work, data collection and/or data entry. The authors are grateful to Junjira Laothavorn for her assistance in editing the manuscript.

\section{FERCAP Multi-Country Research Team}

The authors (and their affiliations), listed in alphabetic order, are as follows: Project Managers - Juntra Karbwang (Department of Clinical Product Development, Institute of Tropical Medicine, Nagasaki University, Nagasaki, Japan), Nut Koonrungsesomboon (Department of Pharmacology, Faculty of Medicine, Chiang Mai University, Chiang Mai, Thailand), and Cristina E. Torres (Forum for Ethical Review Committees in the Asian and Western Pacific region, WHO-TDR Clinical Coordination and Training Center, Thammasat University, Pathum Thani, Thailand; National Institutes of Health, University of the Philippines Manila, Manila, Philippines); Country Coordinators - Edlyn B. Jimenez (National Institutes of Health, University of the Philippines Manila, Manila, Philippines), Gurpreet Kaur (Selangor State Health Department, Ministry of Health, Malaysia), Roli Mathur (ICMR Bioethics Unit, National Centre for Disease Informatics and Research, Bangalore, India), Eti Nurwening Sholikhah (Department of Pharmacology and Therapy, Faculty of Medicine, Universitas Gadjah Mada, Yogyakarta, Indonesia), Chandanie Wanigatunge (Forum for Ethics Review Committees in Sri Lanka and Faculty of Medical Sciences, University of Sri Jayewardanepura, Nugegoda, Sri Lanka), Chih-Shung Wong (Department of Anesthesiology, Cathay General Hospital, Taipei, Taiwan), and 
Kwanchanok Yimtae (Academic Clinical Research Office, Faculty of Medicine Khon Kaen University, Khon Kaen, Thailand); Site Investigators - Murnilina Abdul Malek (Kuala Lumpur Hospital, Kuala Lumpur, Malaysia), Liyana Ahamad Fouzi (Sultanah Nur Zahirah Hospital, Terengganu, Malaysia), Aisyah Ali (Sultan Ismail Hospital, Johor, Malaysia), Beng Zhong Chan (Melaka Hospital, Malaysia), Madawa Chandratilake (Faculty of Medicine, University of Kelaniya, Ragama, Sri Lanka), Shoen Chuen Chiew (Seri Manjung Hospital, Perak, Malaysia), Melvyn Yin Chung Chin (Sungai Buloh Hospital, Selangor, Malaysia), Manori Gamage (Faculty of Medical Sciences, University of Sri Jayewardenepura, Nugegoda, Sri Lanka), Irene Gitek (Sarawak General Hospital, Malaysia), Mohammad Hakimi (Medical and Health Research Ethics Committee, Faculty of Medicine Universitas Gadjah Mada - Dr. Sardjito General Hospital, Yogyakarta, Indonesia), Narwani Hussin (Taiping Hospital, Malaysia), Mohd Fadzly Amar Jamil (Seberang Jaya Hospital, Pulau Pinang, Malaysia), Pavithra Janarsan (Raja Perempuan Zainab II Hospital, Kota Bharu, Malaysia), Madarina Julia (Department of Pediatric, Faculty of Medicine Universitas Gadjah Mada - Dr. Sardjito General Hospital, Yogyakarta, Indonesia), Suman Kanungo (Division of Epidemiology, National Institute of Cholera \& Enteric Diseases, Kolkata, India), Panduka Karunanayake (Faculty of Medicine, University of Colombo, Colombo, Sri Lanka), Sattian Kollanthavelu (Ampang Hospital, Malaysia), Kian Keong Kong (Duchess of Kent Hospital, Sandakan, Malaysia), Bing-Ling Kueh (Likas Hospital, Sabah, Malaysia), Ragini Kulkarni (Department of Operational Research, National Institute for Research in Reproductive Health, Mumbai, India), Paul P. Kumaran (National Institute for Research in Tuberculosis, Chennai, India), Ranjith Kumarasiri (Faculty of Medicine, University of Peradeniya, Peradeniya, Sri Lanka), Wei Honn Lim (Sibu Hospital, Sibu, Sarawak, Malaysia), Xin Jie Lim (Raja Permaisuri Bainun Hospital, Ipoh, Malaysia), Fatihah Mahmud (Tengku Ampuan Afzan Hospital, Kuantan, Malaysia), Jacinto Blas V. Mantaring III (University of the Philippines Manila Research Ethics Board, Manila, Philippines), Siti Maisarah Md Ali (Sultanah Bahiyah Hospital, Alor 705 Setar, Kedah, Malaysia), Nurain Mohd Noor (Putrajaya Hospital, Putrajaya, Malaysia), Kopalasuntharam Muhunthan (Faculty of Medicine, University of Jaffna, Jaffna, Sri Lanka), Elanngovan Nagandran (Tengku Ampuan Rahimah Hospital, Klang, Malaysia), Maisarah Noor (Tuanku Jaáfar Hospital, Seremban, Malaysia), Kim Hong Ooi (Tuanku Fauziah Hospital, Kangar, Perlis, Malaysia), Jebananthy Anandaselvam Pradeepan (Faculty of Medicine, University of Jaffna, Jaffna, Sri Lanka), Ahmad Hamim Sadewa (Department of Biochemistry, Faculty of Medicine, Universitas Gadjah Mada, Yogyakarta, Indonesia), Nilakshi Samaranayake (Faculty of Medicine, University of Colombo, Colombo, Sri Lanka), Shalini Sri Ranganathan (Faculty of Medicine, University of Colombo, Colombo, Sri Lanka), Wasanthi Subasingha (Faculty of Medicine, University of Kelaniya, Ragama, Sri Lanka), Sivasangari Subramaniam (Pulau Pinang Hospital, George Town, Malaysia), Nadirah Sulaiman (Queen Elizabeth I Hospital, Sabah, Malaysia), Ju Fan Tay (Selayang Hospital, Malaysia), Leh Hong Teng (Miri Hospital, Sarawak, Malaysia), Mei Mei Tew (Sultan Abdul Halim Hospital, Sungai Petani, Kedah, Malaysia), Thipaporn Tharavanij (Endocrinology and Metabolism Unit, Department of Medicine, Faculty of Medicine, Thammasat University, Pathum Thani, Thailand), Peter Seah Keng Tok (Sultanah Aminah Hospital, Johor Bharu, Malaysia), Jayanie Weeratna (Institute of Forensic Medicine and Toxicology, Colombo, Sri Lanka), Tri Wibawa (Department of Microbiology, Faculty of Medicine, Universitas Gadjah Mada, Yogyakarta, Indonesia), Renu Wickremasinghe (Faculty of Medical Sciences, University of Sri Jayewardenepura, Nugegoda, Sri Lanka), Phanthipha Wongwai (Department of Opthalmology, Faculty of Medicine, Khon Kaen University, Khon Kaen, Thailand), and Subhash Yadav (Department of Endocrinology, Sanjay Gandhi Post Graduate Institute of Medical Sciences (SGPGI), Lucknow, Uttar Pradesh, India).

\section{Funding}

This work was supported by the Forum for Ethical Review Committees in the Asian and Western Pacific region (FERCAP) and the Strategic Initiative for Developing Capacity in Ethical Review (SIDCER); Research Grant under Adhoc Research Scheme from Indian Council of Medical Research; Faculty of Medicine Universitas Gadjah Mada Grants from the Faculty of Medicine Universitas Gadjah Mada; and Philippine Health Research Ethics Network (PHREN). The funding sources had no role in the design of the study and collection; analysis and interpretation of the data; preparation, review or approval of the manuscript; and decision to submit this manuscript for publication.

\section{Availability of data and materials}

The datasets supporting the conclusions of this article is available upon request from the corresponding authors.

\section{Authors' contributions}

Project Managers (JK, NK, and CET) were responsible for designing the study, developing the study protocol and the questionnaire, collaborating with Country Coordinators, analyzing the data, preparing the results, and drafting and finalizing the manuscript. Country Coordinators (EBJ, GK, RM, ENS, CW, CSW, and KY) were responsible for preparing and translating the questionnaire into the local language, applying for grants, if required, obtaining ethical approval for the conduct of the study in a country, collaborating with Project Managers and Site Investigators, aggregating and reviewing the data from multiple sites in their own country, and reviewing a manuscript. Site Investigators (MAM, LAF, AA, BZC, MC, SCC, MYCC, MG, IG, MH, NH, MFAJ, PJ, MJ, SK, PK, SK, KKK, BLK, RK, PPK, RK, WHL, XJL, FM, JBM, SMMA, NMN, KM, EN, MN, KHO, JAP, AHS, NS, SSR, WS, SS, NS, JFT, LHT, MMT, TT, PSKT, JW, TW, RW, PW, and SY) were responsible for obtaining ethical approval for the conduct of the study in their own site, conducting the study, collecting, entering, and verifying the data from their own site, and reviewing the final manuscript. All authors read and approved the final manuscript.

\section{Ethics approval and consent to participate}

The study protocol and related documents obtained ethical approval from local ethics committees prior to the commencement of the survey in each center. The full name of ethics committee(s) that approved the study in each country is as follows: India - Institutional Ethics Committee, National Center for Disease Informatics and Research (NCDIR); National Institute for Research in Reproductive Health (NIRRH) Ethics Committee for Clinical Studies; Institutional Ethics Committee, ICMR - National Institute of Cholera and Enteric Diseases; National Institute for Research in Tuberculosis (NIRT) Institutional Ethics Committee; and Institutional Ethics Committee, Sanjay Gandhi Postgraduate Institute of Medical Sciences; Indonesia - Medical and Health Research Ethics Committee Faculty of Medicine Universitas Gadjah Mada - Dr. Sardjito General Hospital; Malaysia - Medical Research and Ethics Committee (MREC); Philippines - University of the Philippines Manila Research Ethics Board; Lung Center of the Philippines Institutional Ethics Review Board; Makati Medical Center Institutional Review Board; Manila Doctors Hospital Institutional Review Board; National Kidney and Transplant Institute Research Ethics Committee; Philippine Heart Center Institutional Ethics Review Committee; St. Luke's Medical Center Institutional Ethics Review Committee; and Veterans Memorial Medical Center Institutional Review Board; Sri Lanka - Ethics Review Committee, Sri Lanka Medical Association; Taiwan - Institutional Review Board, Cathay General Hospital; Thailand - Khon Kaen University Ethics Committee in Human Research; and Human Research Ethics Committee of Thammasat University No.1 (Faculty of Medicine). Participants were informed about this survey and consent was obtained by action, i.e., the participants voluntarily answered the questionnaire and returned it to the collection box by themselves.

\section{Consent for publication}

Not applicable.

\section{Competing interests}

The authors declare that they have no competing interests.

\section{Publisher's Note}

Springer Nature remains neutral with regard to jurisdictional claims in published maps and institutional affiliations.

\section{Author details}

${ }^{1}$ Department of Clinical Product Development, Institute of Tropical Medicine, Nagasaki University, 1-12-4 Sakamoto, Nagasaki 852-8523, Japan.

2Department of Pharmacology, Faculty of Medicine, Chiang Mai University, 110 Muang Chiang Mai, Chiang Mai 50200, Thailand. ${ }^{3}$ Forum for Ethical Review Committees in the Asian and Western Pacific region, WHO-TDR Clinical Coordination and Training Center, Thammasat University, Pathum Thani, Thailand. ${ }^{4}$ National Institutes of Health, University of the Philippines Manila, Manila, Philippines. ${ }^{5}$ Selangor State Health Department, Ministry of Health, Putrajaya, Malaysia. ${ }^{6}$ ICMR Bioethics Unit, National Centre for Disease Informatics and Research, Bangalore, India. ${ }^{7}$ Department of Pharmacology and Therapy, Faculty of Medicine, Universitas Gadjah Mada, Yogyakarta, Indonesia. ${ }^{8}$ Forum for Ethics Review Committees in Sri Lanka and Faculty of Medical Sciences, University of Sri Jayewardanepura, Nugegoda, Sri Lanka. ${ }^{9}$ Department of Anesthesiology, Cathay General Hospital, Taipei, Taiwan. 
${ }^{10}$ Academic Clinical Research Office, Faculty of Medicine, Khon Kaen University, Khon Kaen, Thailand. "'Kuala Lumpur Hospital, Kuala Lumpur, Malaysia. ${ }^{12}$ Sultanah Nur Zahirah Hospital, Kuala Terengganu, Terengganu, Malaysia. ${ }^{13}$ Sultan Ismail Hospital, Johor Bahru, Johor, Malaysia. ${ }^{14}$ Melaka Hospital, Melaka, Malaysia. ${ }^{15}$ Faculty of Medicine, University of Kelaniya, Ragama, Sri Lanka. ${ }^{16}$ Seri Manjung Hospital, Seri Manjung, Perak, Malaysia. ${ }^{17}$ Sungai Buloh Hospital, Sungai Buloh, Selangor, Malaysia. ${ }^{18}$ Faculty of Medical Sciences, University of Sri Jayewardenepura, Nugegoda, Sri Lanka. ${ }^{19}$ Sarawak General Hospital, Kuching, Malaysia. ${ }^{20}$ Medical and Health Research Ethics Committee, Faculty of Medicine Universitas Gadjah Mada, Dr. Sardjito General Hospital, Yogyakarta, Indonesia. ${ }^{21}$ Taiping Hospital, Taiping, Malaysia. ${ }^{22}$ Seberang Jaya Hospital, Perai, Pulau Pinang, Malaysia. ${ }^{23}$ Raja Perempuan Zainab II Hospital, Kota Bharu, Malaysia. ${ }^{24}$ Department of Pediatric, Faculty of Medicine Universitas Gadjah Mada, Dr. Sardjito General Hospital, Yogyakarta, Indonesia. ${ }^{25}$ Division of Epidemiology, National Institute of Cholera \& Enteric Diseases, Kolkata, India. ${ }^{26}$ Faculty of Medicine, University of Colombo, Colombo, Sri Lanka. ${ }^{27}$ Ampang Hospital, Ampang, Malaysia. ${ }^{28}$ Duchess of Kent Hospital, Sandakan, Malaysia. ${ }^{29}$ Likas Hospital, Kota Kinabalu, Sabah, Malaysia. ${ }^{30}$ Department of Operational Research, National Institute for Research in Reproductive Health, Mumbai, India. ${ }^{31}$ National Institute for Research in Tuberculosis, Chennai, India. ${ }^{32}$ Faculty of Medicine, University of Peradeniya, Peradeniya, Sri Lanka. ${ }^{33}$ Sibu Hospital, Sibu, Sarawak, Malaysia. ${ }^{34}$ Raja Permaisuri Bainun Hospital, Ipoh, Malaysia. ${ }^{35}$ Tengku Ampuan Afzan Hospital, Kuantan, Malaysia. ${ }^{36}$ University of the Philippines Manila Research Ethics Board, Manila, Philippines. ${ }^{37}$ Sultanah Bahiyah Hospital, Alor Setar, Kedah, Malaysia. ${ }^{38}$ Putrajaya Hospital, Putrajaya, Malaysia. ${ }^{39}$ Faculty of Medicine, University of Jaffna, Jaffna, Sri Lanka. ${ }^{40}$ Tengku Ampuan Rahimah Hospital, Klang, Malaysia. ${ }^{41}$ Tuanku Jaáfar Hospital, Seremban, Malaysia. ${ }^{42}$ Tuanku Fauziah Hospital, Kangar, Perlis, Malaysia. ${ }^{43}$ Department of Biochemistry, Faculty of Medicine, Universitas Gadjah Mada, Yogyakarta, Indonesia. ${ }^{44}$ Pulau Pinang Hospital, George Town, Malaysia. ${ }^{45}$ Queen Elizabeth I Hospital, Kota Kinabalu, Sabah, Malaysia. ${ }^{46}$ Selayang Hospital, Shah Alam, Malaysia. ${ }^{47}$ Miri Hospital, Miri, Sarawak, Malaysia. ${ }^{48}$ Sultan Abdul Halim Hospital, Sungai Petani, Kedah, Malaysia. ${ }^{49}$ Endocrinology and Metabolism Unit, Department of Medicine, Faculty of Medicine, Thammasat University, Pathum Thani, Thailand. ${ }^{50}$ Sultanah Aminah Hospital, Johor Bharu, Malaysia. ${ }^{51}$ Institute of Forensic Medicine and Toxicology, Colombo, Sri Lanka. ${ }^{52}$ Department of Microbiology, Faculty of Medicine, Universitas Gadjah Mada, Yogyakarta, Indonesia. ${ }^{53}$ Department of Opthalmology, Faculty of Medicine, Khon Kaen University, Khon Kaen, Thailand. ${ }^{54}$ Department of Endocrinology, Sanjay Gandhi Post Graduate Institute of Medical Sciences (SGPGI), Lucknow, Uttar Pradesh, India.

Received: 15 May 2018 Accepted: 28 August 2018 Published online: 15 September 2018

\section{References}

1. World Medical Association. World medical association declaration of Helsinki: ethical principles for medical research involving human subjects. JAMA. 2013;310:2191-4.

2. Guideline for good clinical practice E6(R2). European Medicines Agency. Available from: http://www.ema.europa.eu/docs/en_GB/document_library/ Scientific_guideline/2009/09/WC500002874.pdf. Accessed 15 Feb 2018.

3. Berger O, Grønberg BH, Sand K, Kaasa S, Loge JH. The length of consent documents in oncological trials is doubled in twenty years. Ann Oncol. 2009;20:379-85.

4. Kass NE, Chaisson L, Taylor HA, Lohse J. Length and complexity of US and international HIV consent forms from federal HIV network trials. J Gen Intern Med. 2011;26:1324-8.

5. Ménoni $\mathrm{V}$, Lucas $\mathrm{N}$, Leforestier JF, et al. The readability of information and consent forms in clinical research in France. PLoS One. 2010;5:e10576.

6. Wen G, Liu X, Huang L, et al. Readability and content assessment of informed consent forms for phase II-IV clinical trials in China. PLoS One. 2016;11:e0164251.

7. Federal policy for the protection of human subjects. Federal Register 2017; 82(12):7149-274. Available from: https://www.federalregister.gov/ documents/2017/01/19/2017-01058/federal-policy-for-the-protection-ofhuman-subjects. Accessed 15 Feb 2018.

8. International Ethical Guidelines for Health-related Research Involving Humans, Fourth Edition. Geneva. Council for International Organizations of Medical Sciences (CIOMS); 2016.
9. Sugarman J. Examining provisions related to consent in the revised common rule. Am J Bioeth. 2017;17:22-6.

10. Grady C, Cummings SR, Rowbotham MC, McConnell MV, Ashley EA, Kang G. Informed consent. N Engl J Med. 2017;376:856-67.

11. Antoniou EE, Draper H, Reed K, Burls A, Southwood TR, Zeegers MP. An empirical study on the preferred size of the participant information sheet in research. J Med Ethics. 2011;37:557-62.

12. Ferguson PR. Patients' perceptions of information provided in clinical trials. J Med Ethics. 2002;28:45-8.

13. Dranseika V, Piasecki J, Waligora M. Relevant information and informed consent in research: in defense of the subjective standard of disclosure. Sci Eng Ethics. 2017;23:215-25.

14. Wilkinson S. Consent. In: European textbook on ethics in research. Luxembourg: publications office of the European union; 2010. p. 33-48.

15. Dickert NW, Eyal N, Goldkind SF, et al. Reframing consent for clinical research: a function-based approach. Am J Bioeth. 2017;17:3-11.

16. Kirkby HM, Calvert M, Draper H, Keeley T, Wilson S. What potential research participants want to know about research: a systematic review. BMJ Open. 2012;2(3)

17. ' 45 CFR 46'. Available from https://www.gpo.gov/fdsys/pkg/CFR-2016-title45vol1/pdf/CFR-2016-title45-vol1-part46.pdf.

18. Rubio DM, Berg-Weger M, Tebb SS, Lee ES, Rauch S. Objectifying content validity: conducting a content validity study in social work research. Soc Work Res. 2003;27:94-104.

19. Vagias WM. Likert-type scale response anchors. Clemson International Institute for Tourism \& Research Development, Department of Parks, Recreation and Tourism Management. Clemson University; 2006.

20. Willis $G B$, Artino AR,J. What do our respondents think we're asking? Using cognitive interviewing to improve medical education surveys. J Grad Med Educ. 2013;5:353-6.

21. Park J-W, Jung M-S. A note on determination of sample size for a Likert scale. Commun Stat Application Methods. 2009;16:669-73.

22. Harpe SE. How to analyze Likert and other rating scale data. Currents Pharm Teaching Learning. 2015;7:836-50.

23. Norman G. Likert scales, levels of measurement and the "laws" of statistics. Adv Health Sci Educ Theory Pract. 2010;15:625-32.

24. Sullivan GM, Artino AR,J. Analyzing and interpreting data from Likert-type scales. J Grad Med Educ. 2013;5:541-2.

25. Kirkby HM, Calvert M, McManus RJ, Draper H. Informing potential participants about research: observational study with an embedded randomized controlled trial. PLoS One. 2013;8:e76435.

26. El-Wakeel H, Taylor GJ, Tate JJ. What do patients really want to know in an informed consent procedure? A questionnaire-based survey of patients in the bath area, UK. J Med Ethics. 2006;32:612-6.

27. Newton-Howes PA, Bedford ND, Dobbs BR, Frizelle FA. Informed consent: what do patients want to know? N Z Med J. 1998;111:340-2.

28. Wendler D. What should be disclosed to research participants? Am J Bioeth. 2013;13:3-8.

29. Wolf SM, Branum R, Koenig BA, et al. Returning a research participant's genomic results to relatives: analysis and recommendations. J Law Med Ethics. 2015;43:440-63.

30. Wolf SM, Crock BN, Van Ness B, et al. Managing incidental findings and research results in genomic research involving biobanks and archived data sets. Genetics Med. 2012;14:361-84.

31. National Heart. Lung, blood institute working group, Fabsitz RR, McGuire a, et al. ethical and practical guidelines for reporting genetic research results to study participants: updated guidelines from a National Heart, Lung, and Blood Institute working group. Circ Cardiovasc Genet. 2010;3:574-80.

32. Jarvik GP, Amendola LM, Berg JS, et al. Return of genomic results to research participants: the floor, the ceiling, and the choices in between. Am J Hum Genet. 2014;94:818-26.

33. Corneli A, Namey E, Mueller MP, et al. Evidence-based strategies for shortening informed consent forms in clinical research. J Empir Res Hum Res Ethics. 2017;12:14-25.

34. Matsui K, Lie RK, Turin TC, Kita Y. A randomized controlled trial of short and standard-length consent forms for a genetic cohort study: is longer better? J Epidemiol. 2012;22:308-16.

35. Grady C, Touloumi G, Walker AS, et al. A randomized trial comparing concise and standard consent forms in the START trial. PLOS One. 2017; 12:e0172607. 
36. Koonrungsesomboon N, Laothavorn J, Chokevivat V, Hirayama K, Karbwang J. SIDCER informed consent form: principles and a developmental guideline. Indian J Med Ethics. 2016;1:83-6.

37. Koonrungsesomboon N, Teekachunhatean S, Hanprasertpong N, Laothavorn J, Na-Bangchang K, Karbwang J. Improved participants' understanding in a healthy volunteer study using the SIDCER informed consent form: a randomized-controlled study. Eur J Clin Pharmacol. 2016;72:413-21.

38. Koonrungsesomboon N, Tharavanij T, Phiphatpatthamaamphan K, et al. Improved participants' understanding of research information in real settings using the SIDCER informed consent form: a randomized-controlled informed consent study nested with eight clinical trials. Eur J Clin Pharmacol. 2017;73:141-9.

39. Koonrungsesomboon N, Traivaree C, Chamnanvanakij S, Rungtragoolchai P, Thanapat Y, Karbwang J. Improved pregnant women's understanding of research information by an enhanced informed consent form: a randomised controlled study nested in neonatal research. Arch Dis Child Fetal Neonatal Ed. 2017; https://doi.org/10.1136/archdischild-2017-312615.

40. Tait AR, Voepel-Lewis T, Zikmund-Fisher BJ, Fagerlin A. The effect of format on parents' understanding of the risks and benefits of clinical research: a comparison between text, tables, and graphics.J Health Commun. 2010;15:487-501.

41. Koh J, Goh E, Yu KS, Cho B, Yang JH. Discrepancy between participants' understanding and desire to know in informed consent: are they informed about what they really want to know? J Med Ethics. 2012;38:102-6.

42. Bidmon S, Terlutter R. Gender differences in searching for health information on the internet and the virtual patient-physician relationship in Germany: exploratory results on how men and women differ and why. Med Internet Res. 2015;17:e156.

43. Brown RF, Shuk E, Butow P, Edgerson S, Tattersall MH, Ostroff JS. Identifying patient information needs about cancer clinical trials using a question prompt list. Patient Educ Couns. 2011;84:69-77.

44. Maslin A. A survey of the opinions on 'informed consent' of women currently involved in clinical trials within a breast unit. Eur J Cancer Care. 1994;3:153-62.

45. Harzing AW. Response styles in cross-national survey research: a 26-country study. Int J Cross Cult Manag. 2006;6:243-66.

46. Shilling $V$, Young B. How do parents experience being asked to enter a child in a randomised controlled trial? BMC Med Ethics 2009;10:1.

47. Baker JN, Leek AC, Salas HS, et al. Suggestions from adolescents, young adults, and parents for improving informed consent in phase 1 pediatric oncology trials. Cancer. 2013;119:4154-61.

48. Casarett D, Karlawish J, Sankar P, Hirschman KB, Asch DA. Obtaining informed consent for clinical pain research: patients' concerns and information needs. Pain. 2001;92:71-9.

Ready to submit your research? Choose BMC and benefit from:

- fast, convenient online submission

- thorough peer review by experienced researchers in your field

- rapid publication on acceptance

- support for research data, including large and complex data types

- gold Open Access which fosters wider collaboration and increased citations

- maximum visibility for your research: over $100 \mathrm{M}$ website views per year

At BMC, research is always in progress.

Learn more biomedcentral.com/submissions 